\title{
Bernard Rentier: um exemplo a ser seguido
}

Apresentação Helio Kuramoto

É uma grande satisfação apresentar a entrevista realizada pelo jornalista Richard Poynder com o reitor da Universidade de Liège, Prof. Bernard Rentier, pois ela mostra a capacidade deste entusiasta do Open Access (OA) de entender o problema, logo nos seus primórdios, e vislumbrar o fato de o OA ser uma boa solução para os problemas que ele enfrentava ao ser nomeado vice-reitor, responsável pela área de pesquisa e pelas bibliotecas daquela universidade. Ele conseguiu perceber muito rapidamente os benefícios que o OA poderia trazer à universidade que ele dirigia. Após mais de cinco anos de luta em favor do OA, no Brasil, consigo entender a que tipo de pessoa esse reitor se referia.

Bernard conseguiu entender os benefícios do OA porque ele vivenciou problemas ao assumir a coordenação das áreas de pesquisa e de bibliotecas. Um desses problemas dizia respeito aos custos exorbitantes das assinaturas das revistas científicas, nos idos de 1998, os quais engoliam os orçamentos das bibliotecas daquela universidade, ano após ano. É interessante notar que este problema das assinaturas de periódicos científicos não é um problema localizado. Ele existe em todas as partes do planeta Terra, e o Brasil enfrenta o mesmo problema, só que em dimensões relativamente maiores, enquanto Bernard Rentier tinha o problema circunscrito apenas à sua universidade.

O mais interessante dessa história é que Bernard Rentier, ao invés de adotar uma solução simplista de buscar e/ou garantir mais recursos para manter a atualização das coleções de revistas científicas, optou por uma solução inovadora e progressista, posicionando-se em direção oposta à manutenção do status quo, de alimentar o lucro da indústria editorial científica internacional. Em nosso entendimento e, pelo caminhar das iniciativas 
preconizadas pela estratégia da Via Verde, o reitor, ao tomar a decisão de implantar o mandato verde OA e construir o ORBi, vem promovendo os seguintes benefícios à comunidade acadêmica da Universidade de Liège:

- um alívio gradativo e definitivo, no orçamento das bibliotecas, mediante a desoneração crescente da rubrica de assinaturas de revistas científicas, por intermédio do cancelamento das assinaturas de revistas em decorrência da disponibilização dos artigos dessas revistas em repositórios de acesso livre (benefício não imediato);

- maior visibilidade às pesquisas desenvolvidas pela ULG (benefício a curto prazo);

- estimula o registro e a disseminação sistemática da produção científica da ULG (benefício imediato);

- fortalece a imagem institucional da ULG e, como o próprio reitor diz, a reputação da ULG (benefício a médio prazo);

- valoriza o pesquisador da ULG, na medida em que dissemina a produção científica de seus pesquisadores (benefício a curto e médio prazo);

- maiores oportunidades de cooperação técnico-científica com instituições belgas e/ou estrangeiras (benefício a médio e longo prazo);

- criação de mecanismos de avaliação de desempenho e governança na gestão das pesquisas e da própria ULG (benefício a médio e longo prazo);

- estimula a autoestima dos pesquisadores da ULG, na medida em que estes assistem à citação, uso e impacto de seus trabalhos (benefício a médio e longo prazo).

Muito embora o Bernard Rentier tenha empreendido a estratégia da Via Verde em uma universidade, nada impede que esta estratégia seja implantada em um país, com abrangência nacional. Foi este, aliás, o nosso objetivo, quando articulamos o Projeto de Lei no 1120/2007 com o ex-deputado Rodrigo Rollemberg. No entanto, a Câmara dos Deputados o arquivou no dia 31 de janeiro de 2011. Entretanto, é bom ressaltar que a luta continua, e esta é uma guerra composta de várias batalhas. O PL 1120/2007 foi apenas 
uma batalha, outras mais virão e espero que a nossa comunidade científica acorde.

\section{Introdução à entrevista por Richard Poynder}

O que é notável sobre o Open Access é o fato de ser, obviamente, o caminho certo e racional para a comunidade científica responder ao mundo em rede. De fato, pode-se descrevê-lo apropriadamente como um acéfalo - ou, como diz o advogado do OA, Stevan Harnad: OA é a "ciência capa de chuva" ("Está chovendo, meninos, vocês estão se molhando: é hora de colocar suas capas de chuva!").

O que é estranho, sobre OA, é que tão poucos na comunidade científica ainda parecem não ter compreendido (ou pelo menos aceito) a sua inevitabilidade. Essa miopia não é, indubitavelmente, por acaso - muitos têm interesse no status quo, enquanto outros instintivamente têm medo da mudança e uma aversão irracional ao novo.

Consequentemente, o que é com certeza "inevitável e ótimo" foi adiado por mais de uma década e meia. Enquanto o OA universal poderia teoricamente ser percebido, em apenas uma noite, estima-se, hoje, que apenas 30\% da literatura científica/ acadêmica estejam livremente disponíveis na web. Felizmente alguns conseguem captar no momento em que o conceito é explicado a eles - como é o caso de Bernard Rentier, professor de virologia e imunologia da Universidade de Liège (ULG), em 1998. Rentier tinha sido nomeado vice-reitor responsável pela política de pesquisa científica e pelas bibliotecas na ULG no ano anterior - uma posição que, inevitavelmente, focalizou a sua mente professoral em uma série de problemas para os quais o OA passa a ser solução. Isso ficou claro para ele durante uma conversa que teve com um encarregado pela biblioteca de ciência, que introduziu o conceito por trás do movimento AO, então incipiente.

"Foi imediatamente óbvio para mim que esta era a abordagem lógica a tomar", diz Rentier, "especialmente porque a nova tecnologia que estava surgindo, em seguida, tornou-se inteiramente possível." Para começar, diz Rentier, ele viu que OA poderia ajudar a aliviar a crise dos seriados - 
um fardo indesejável sobre as universidades que a cada ano via pedaços cada vez maiores de seus orçamentos para a biblioteca sendo engolidos pelo aumento dos preços das assinaturas das revistas científicas.

Ele também percebeu que tornando os seus artigos disponíveis livremente na web, os pesquisadores da ULG poderiam incrementar tanto o impacto como a sua visibilidade dentro da comunidade científica global - algo que todos os seus pesquisadores e suas instituições desejavam. Finalmente, Rentier pôde ver que o OA permitiria à ULG mostrar ao mundo a qualidade das pesquisas que seus cientistas desenvolviam e, portanto, melhorando a sua reputação institucional.

O que foi especialmente fortuito, sobre a conversa com Rentier sobre OA, é que ele é um homem com uma energia e entusiamo ilimitados, e em posição de criar uma mudança mais eficaz do que muitos defensores do AO - especialmente depois que ele tornou-se Reitor da ULG em 2005.

Naquele momento, Rentier concluiu que, embora a estratégia Dourada (edição OA) pudesse vir a ser uma boa solução a longo prazo, a melhor estratégia a curto prazo era abraçar a estratégia Verde (autoarquivamento). Em outras palavras, em vez de aconselhar os pesquisadores a procurar uma editora OA, ou revista de acesso livre para publicar seus artigos, era melhor incentivá-los a continuar publicando como sempre fizeram e fazer com que todos os seus artigos fossem disponibilizados gratuitamente na web, por meio do autoarquivamento.

Com o propósito de estimular os pesquisadores da ULG a depositarem os seus artigos em um repositório institucional (RI), Rentier supervisionou a sua criação, denominando-o de ORBi - Open Repository and Bibliography. O ORBi entrou em funcionamento em novembro de 2008. Pesquisadores da ULG foram convidados a depositar todos os seus artigos neste RI. Para ajudar a convencê-los a depositá-los, Rentier lançou o seu próprio blog, e iniciou uma campanha de encorajamento e exortação.

Além disso, determinou que o ORBi deveria capturar todas as pesquisas em desenvolvimento na universidade. Rentier também introduziu um mandato de autoarquivo - exigindo que todos os pesquisadores da ULG depositem os seus trabalhos no Orbi. Para motivar ainda mais o cumprimento do mandato, Rentier 
anunciou que o depósito de documentos no repositório seria o único mecanismo a ser considerado para efeito de avaliação de desempenho dos pesquisadores. Catorze meses depois de seu lançamento, o ORBI já tinha acumulado 30 mil referências bibliográficas, e mais de 20.000 documentos em texto completo. Hoje, o ORBi é o RI mais ativo, entre seus similares, no mundo (primeiro do ranking de 1.418 RI). Os pesquisadores da ULG estão começando a ver os benefícios de ter aderido à estratégia da via Verde do OA, tanto em termos de citações e aumento de prestígio quanto em termos da emoção de ver alguns de seus artigos mais velhos começarem, como diz Rentier, "a viver uma nova vida".

Mas Rentier não é um homem que se contente em ver o OA implementado, apenas, em sua própria universidade. Ele quer que a comunidade científica em geral aproveite as oportunidades que o OA oferece. Para esse fim, ele também assumiu a presidência da Enabling Open Scholarship (EOS).

Fundada em 2009, o EOS tem como objetivo convencer reitores, vice-reitores de universidades, de todo o mundo, dos benefícios da OA, e ensiná-las a melhor forma de alcançá-los.

Ele também está tentando convencer o Fundo Nacional de Pesquisa da Bélgica a adotar um mandato via verde, que exigiria que todos os trabalhos resultantes de pesquisas financiadas por este fundo tornem-se de acesso livre.

Rentier não foi o primeiro dirigente sênior da academia a introduzir um mandato de acesso livre aderente à via verde (os aplausos devem ser dirigidos também a Tom Cochrane, vicereitor da Universidade de Tecnologia de Queensland, na Austrália, que introduziu o primeiro mandato universitário do mundo em 2004). No entanto, diz Harnad: "Bernard é o primeiro reitor/vicereitor a compreender completa e totalmente como agir de acordo com a OA".

Ele acrescenta: "Bernard entendeu e implementou precisamente o mandato correto na Universidade de Liège (Depósito Imediato/Acesso opcional vinculado a avaliação de desempenho) e, além disso, assumiu imediatamente a liderança em políticas OA para universidades, não apenas na Europa mas em todo o globo terrestre."

Em suma, Bernard Rentier não é um entusiasta de poltrona do acesso livre, ele é um defensor enérgico, que se mostrou capaz e disposto de instituir a mudança em sua casa e no exterior. $\mathrm{Na}$ 
verdade, diz Rentier, não é apenas uma mudança que ele busca, mas "uma revolução global" na comunicação científica.

\section{A Entrevista}

\section{RP: Qual a sua função na Universidade de Liège?}

BR: Eu sou o reitor, ou seja, algo como vice-reitor e presidente do Conselho ao mesmo tempo.

RP: Você poderia dizer alguma coisa sobre a Universidade de Liège (ULG), como: número de estudantes, número de professores, interesses em pesquisa, etc?

BR: A universidade tem 20.000 alunos, e é uma universidade completa. Existem 11 faculdades e 4.500 funcionários, dos quais 600 são professores. Também temos um hospital universitário (com outros 4.500 funcionários). Nós temos a única Faculdade de Medicina Veterinária na parte francofônica da Bélgica. No total, são 2.800 professores na ULG, com mais ou menos 1.000 no hospital universitário. Nossa pesquisa é excelente, e nos especializamos em tecnologia espacial, biotecnologia, medicina, ciência ambiental, agronomia e medicina veterinária.

RP: Você é um defensor de Acesso Livre. Quando você se tornou defensor, e por quê?

BP: Eu me interessei pelo tema em 1997, quando me tornei vice-reitor e fui encarregado pela política de pesquisa científica e pelas bibliotecas. Eu me tornei um defensor progressivamente.

RP: Então não houve um momento Eureka. Mas, talvez, tenha existido um momento no qual você, de repente, viu a logica e a necessidade do acesso livre.

BR: Houve definitivamente esse momento. Ocorreu logo no início quando a moça encarregada da biblioteca de ciências me contou sobre, o agora denominado, movimento do acesso livre, o qual era ainda bem recente e não havia ainda uma denominação. 
RP: Em que ano isto aconteceu?

BR: Não me lembro, exatamente, mas isto teria sido por volta de 1998 ou 1999.

Mas, era, imediatamente, óbvio para mim que esta era a abordagem lógica a desenvolver, especialmente, considerando a nova tecnologia que era então emergente tornava-a inteiramente possível, embora aquela tecnologia, obviamente, não fosse tão desenvolvida como o é agora.

RP: Os bibliotecários têm estado na vanguarda do movimento OA. Você acha que isso é porque são eles que tiveram de pagar as assinaturas, sempre crescentes das publicações especializadas, ou é simplesmente porque os bibliotecários são naturalmente progressistas?

BR: Eu não quero ser tão assertivo sobre isso, ou fazer generalizações indevidas! Alguns bibliotecários são naturalmente progressistas. Certamente, nós selecionamos nosso bibliotecário chefe Thirion Paul - que foi instrumental no desenvolvimento da nossa política de documentação e idealizador do ORBi - por causa de seu espírito progressista. Em termos mais gerais, eu diria que os bibliotecários não podem ser apenas progressistas: às vezes eles também têm que ter uma abordagem muito conservadora. A boa preservação exige uma abordagem conservadora. No entanto, como eu entendo, o desenvolvimento de um RI exige tanto respeito pelo passado quanto inovação e ousadia.

RP: Em maio de 2007 a Universidade de Liège decidiu criar um RI chamado ORBi, que foi ao ar em novembro de 2008. Qual era o objetivo?

BR: ORBi foi criado com as seguintes finalidades: i) Contribuir para o OA, tornando toda a literatura produzida pela Universidade de Liège disponível gratuitamente em linha; ii) Fornecer à Universidade - pela primeira vez - um catálogo completo de todas as publicações que seus pesquisadores haviam desenvolvido; iii) Fornecer à Universidade uma vitrine permanente e atualizada da sua produção científica; iv) Oferecer aos nossos cientistas uma melhor chance de ser lido e citado. 
(1) Termo utilizado para a cópia da versão final do artigo publicado em uma revista; usualmente as revistas enviam para o autor essa cópia exatamente para ser distribuída entre os seus pares
RP: Em meu entendimento, o ORBi revelou-se uma iniciativa muito bem-sucedida, acumulando mais de $\mathbf{3 0 . 0 0 0}$ referências bibliográficas e mais de 20.000 textos completos em um espaço de tempo de 14 meses do seu lançamento. Quais são os números atuais?

BR: Hoje, existem 62.207 referências e 37.497 publicações em texto completo. Os números são atualizados constantemente na primeira página do ORBi.

RP: O sucesso do ORBi se deve, talvez, ao fato de que a Universidade também estabeleceu um mandato de autoarquivamento. Isto requer que todos os pesquisadores da universidade depositem cópias de seus trabalhos de pesquisa no ORBI, publicados em revistas com revisão por pares. Você pode dizer algo sobre as especificidades deste mandato, e por que ele foi introduzido?

BR: Foi introduzido porque eu sabia que sem ele o repositório, mesmo nas melhores circunstâncias possíveis, eventualmente só atrairia 5 a 10\% das publicações alvo. Este é um fato bem demonstrado. Por exemplo, meus colegas da ULB, em Bruxelas, não têm mandato, e seu RI tem 56.669 referências dos quais apenas 7.517 são documentos em texto completo.

RP: Pelo que entendi, o mandato da Universidade de Liège é o que o defensor do OA, Stevan Harnad, chama de mandato Depósito Imediato/Acesso Opcional (ID/OA)? Ou seja, a Universidade espera que todos os artigos produzidos por seus pesquisadores sejam depositados no ORBi, mas se o editor insiste no embargo do artigo, o artigo pode ser depositado com "acesso restrito" até que o embargo se expire. Isso garante que mesmo quando um trabalho é embargado a Universidade tenha a sua própria cópia, a qual ela pode usar internamente. E uma vez que os detalhes bibliográficos estão disponíveis gratuitamente na web outros pesquisadores podem contatar o autor e pedir para ser enviado um reprint ${ }^{1}$ ?

BR: Exatamente, é um mandato ID/OA. E, a política do embargo é a que você descreveu.

RP: Que porcentagem da produção científica total da ULG é depositada, hoje, no ORBi?

BR: É muito difícil dizer. Primeiro não sabemos (e nunca se soube!) quantas pesquisas realmente produzi- 
mos. Então ORBi nos fornece uma oportunidade para, pela primeira, vez descobri-lo. Em segundo lugar, alguns autores têm alimentado o ORBi com toda a sua produção publicada, que pode consistir em décadas merecidas de trabalho. Outros ainda têm um registro muito incompleto. Mas o nosso mandato vai garantir que o repositório seja finalmente alimentado.

RP: Então, o mandato tornou obrigatório, a todos os pesquisadores da Universidade de Liège (ULG), o depósito de seu trabalho no ORBi?

BR: O mandato é de fato um mandato "falso". Nada acontece para aqueles que não depositam suas publicações no ORBi.

\section{RP: Mas você fornece algum tipo de incentivo para os pesquisadores cumpri-lo?}

BR: O que acontece é que quando tomamos decisões sobre a promoção de um pesquisador, ou a concessão de uma subvenção, só levamos em consideração as publicações que o pesquisador depositou no ORBi. Todos os funcionários são informados de que as publicações apresentadas em qualquer outro meio (papel, disco, e-mail, etc.) não podem mais ser tratados em nosso novo sistema. Ou seja, apenas os documentos depositados são considerados para fins de avaliação de desempenho.

RP: Então, hoje, o ORBi é o único mecanismo, por intermédio do qual os pesquisadores da ULG podem submeter os seus artigos para avaliação de desempenho?

BR: Correto. Isto significa que todos os pesquisadores estão ansiosos para ver o repositório alimentado, na medida em que o seu próprio trabalho está em causa, pelo menos. Mas não se trata apenas de uma questão dos pesquisadores se preocuparem com a possibilidade de serem subvalorizados ou desconsiderados publicamente. Como você diz, nós também fornecemos alguns incentivos fortes para estimular o cumprimento do mandato.

\section{RP: Você poderia dizer algo mais sobre esses incentivos?}

BR: O ORBi publica permanentemente estatísticas atualizadas de downloads - uma espécie de hit parade, se 
você prefere, - mostrando quais são os artigos que são mais baixados, e que autores são mais frequentemente consultados. Nós também fornecemos links diretos para quaisquer citações induzidas por esses artigos. O relatório que é gerado automaticamente pelo ORBi, é apresentado de forma lógica, clara e em conformidade com os valores tradicionais de áreas importantes de pesquisa. Também pode ser usado para gerar uma lista de publicações para curriculum vitae (CV), podendo ser atualizado e impresso a qualquer momento em formato definido pelo autor. Como resultado disto, temos sido capazes de demonstrar aos nossos autores que o sistema foi, realmente, projetado para o seu próprio benefício, e de maneira a aumentar a sua visibilidade e leitores. Assim, há uma série de vantagens, óbvias, para os pesquisadores depositarem os seus artigos no ORBi: o repositório lhes proporciona um meio de divulgar seu trabalho, de graça, para todo o mundo e oferece-lhes um arquivo seguro e permanente (tanto para seu trabalho em curso como para a sua obra completa), e fornece um lugar onde eles podem postar seus dados de apoio inéditos, não publicados (e impublicáveis). Ele fornece um ponto único de entrada, mas várias opções de saída, permitindo, os pesquisadores, gerar CV, listas de publicações etc. e fornece uma ferramenta para avaliar a qualidade da sua pesquisa, e uma eficiente ferramenta de marketing pessoal.

RP: O mandato da ULG se aplica apenas aos artigos publicados em revistas, ou inclui livros, apresentações e outras formas de apresentação de resultados de uma pesquisa?

BR: O nosso mandato é composto de dois elementos: 1. As referências (metadados) de todas as publicações de todos os autores da ULG, publicados desde 2002, devem ser depositados no ORBi. E, 2. O texto completo de todos os artigos científicos publicados desde 2002 e todas as teses de doutorado devem ser depositados. Para os artigos mais velhos e para outros tipos de publicações (capítulos, livros, etc.) é opcional (Na prática, os autores geralmente depositam mais texto completo do que o necessário!) 
Dito isto, todas as categorias de publicação são bem-vindas, embora a classificação para fins de avaliação de desempenho seja extremamente rigorosa. Um resumo de conferência ou um livro popular, por exemplo, não pode ser incluído em uma lista de artigos, revisado por pares, em revista internacional. Assim, muitos tipos diferentes de trabalho podem ser depositados, mas cada item é claramente reconhecido e rotulado para o que é. Com certeza, a minha esperança é que muitos outros tipos de informações sejam armazenados no ORBi - incluindo dados brutos de pesquisa, resultados negativos, os resultados não publicados ou impublicáveis, etc. Na verdade, os dados brutos de pesquisa já podem ser depositados. É o que chamamos de "material adicional", e pode ser carregado pelos autores com o acompanhamento de seu texto integral. Mas o importante é rotular as coisas de forma adequada.

RP: Os dados de depósito que você forneceu sugerem que há cerca de 25.000 registros no ORBI que não incluem o texto completo? Isso é problemático?

BR: Esse número está correto. Cerca de 60\% estão disponíveis em texto completo, e cerca de $50 \%$ destes estão OA disponíveis. Mas os itens não texto completo podem ser resumos de conferências, ou podem ser obras que foram publicadas antes de 2002. Como eu disse, nosso mandato exige que qualquer pesquisa publicada depois de 2002 deva incluir o texto completo, mas artigos anteriores podem ser apenas resumos.

RP: Mandatos tendem a variar em suas exigências. Que mandato, na sua opinião, é o ideal?

BR: O meu!

\section{RP: Por quê?}

BR: Porque o nosso mandato não impõe sanções a qualquer pessoa que escolhe ser refratário, ou resistir e não atender ao mandato. Claro, eles não podem esperar qualquer ajuda ou apoio da instituição, e eles se sentirão subestimados pelas autoridades, pelos seus colegas, por pesquisadores externos, e pelo público em geral. Essa é 
a única consequência em não depositar. Contudo, isto geralmente fornece o estímulo suficiente para incentivar todo mundo a cumprir o mandato. O outro ponto a destacar é que o repositório é totalmente público, e ainda acessível diretamente através de um link a partir do diretório de pessoal. Ninguém quer que as pessoas pensem que eles não publicaram nada, ou que publicaram menos do que eles realmente escreveram, sozinhos ou em coautoria.

RP: A adoção do mandato OA foi resultado de uma iniciativa pessoal sua?

BR: Sim, foi.

RP: Os pesquisadores depositam os seus artigos no ORBi, ou o processo é mediado pelos bibliotecários?

BR: Nós preferimos que eles o façam. Em termos de qualidade, é muito melhor que se faça dessa forma, e o depósito se realiza com maior rapidez.

Aqueles que têm secretária solicitam a elas que façam o depósito por eles. Outros podem até mesmo contratar alguém para depositar o seu trabalho para eles. Infelizmente, a qualidade dos metadados é menor em tais circunstâncias, dado que os intermediários são, inevitavelmente, menos familiarizados com os detalhes das publicações.

RP: Então, depositar não é uma tarefa insignificante?

BR: Pode ser uma carga de trabalho enorme inicialmente, se alguém tem publicado muitos artigos, até que todos estejam dentro do ORBi Mas, uma vez que um pesquisador atingiu o modo cruzeiro de operação, ou seja, tenha depositado toda a sua produção, é uma tarefa perfeitamente viável. Se as pessoas estão claramente se esforçando para fazer o depósito, no entanto, iremos fornecer ajuda. Geralmente, isto acontece quando há perda dos manuscritos e, aí é necessário então digitalizar os textos e fazer reconhecimento de caracteres.

RP: Claramente o sistema funciona. Hoje, o ORBi é o repositório institucional mais ativo, entre seus congêneres, 
no mundo (é o primeiro do ranking de 1418 RI). Mas, há alguma evidência para mostrar que, tornando os artigos OA, tenha aumentado o impacto e/ou a contagem de citações para os pesquisadores da Universidade? E, há alguma evidência de que, tornando os resultados das pesquisas da Universidade $O A$, tenha melhorado a sua reputação, status ou perfil dentro da comunidade científica?

BR: No início, não havia nada para falar, e foi necessário muito convencimento de minha parte para manter o ritmo. Para ajudar nisso, eu usei meu blog, que é amplamente lido dentro da universidade, e eu aproveitava todas as oportunidades que apareciam para expor sobre o assunto. Eu assumi um fardo muito pesado para mim, mas está provado que valeu à pena - recentemente comecei a receber uma série de comentários de pesquisadores, dizendo ter uma clara impressão de que eles estão sendo mais lidos do que eram antes. Alguns também estão agora começando a preparar alguns dados mais sólidos para mostrar que eles são citados com mais frequência do que costumavam ser. E muitos relatam que os artigos que eles têm no repositório sob embargo temporário estão sendo solicitados reprints muito mais frequentemente do que costumava acontecer no passado. Claro, isso tende a ser tudo bastante impressionante. Eu não tenho qualquer cálculo objetivo para demonstrar este efeito. Mas eu acho que seria difícil, se não impossível, de qualquer forma, fazê-lo de forma convincente. Eu acrescentaria uma outra coisa: muitas pessoas, inclusive eu próprio, tenho notado que os nossos velhos artigos começaram a viver uma nova vida. Por exemplo, um de meus artigos, publicado em 1985, e que já tinha sido completamente esquecido, começou uma nova carreira, e agora está sendo baixado com frequência!

RP: Disseram-me que há cerca de 10.000 universidades/centros de pesquisa no mundo. De acordo com o sítio ROARMAP, existem apenas cerca de 120 mandatos institucionais. $O$ que a Universidade de Liège - e as outras instituições que estabeleceram seus mandatos $-m$ perceberam que a grande maioria das instituições de ensino superior e de pesquisa parecem ainda não terem percebido? 
BR: Francamente, eu não sei. Talvez a diferença resida no grau de preocupação sentido pelo(s) dirigente(s) un iversitário(s) e sua habilidade, paciência e teimosia em persuadir seus autores a jogar o jogo. Então, talvez se possa dizer que a diferença está na capacidade da instituição em fazer da filosofia OA um grande valor moral a que a maioria dos seus membros se sinta capaz para se inscrever. No início, aqui na ULG, a adesão foi baixa e a resistência foi muito forte. Qualquer pretexto era considerado bom o suficiente para não participar. Mais recentemente, comecei a receber comentários positivos frequentes sobre quão agradável e inesperadamente útil é a ferramenta repositório.

RP: Acho que isso nos diz que os dirigentes de universidade precisam ser persistentes na defesa do OA. Mas diga-me, quando você fala sobre o "grau de preocupação" sentido por dirigentes universitários, a que tipo de preocupação você está se referindo? Dito de outra forma, qual é o argumento essencial para o OA a partir da perspectiva do dirigente de uma universidade?

BR: Preocupação com o custo de periódicos acadêmicos/ científicos; preocupação em ter um inventário da produção da universidade; e preocupação em ter uma vitrine do desempenho da pesquisa da universidade.

RP: Um número de agências de fomento à pesquisa também adotou mandatos $\mathrm{OA}$ aderentes à Via Verde, e alguns criaram seus próprios repositórios centrais - por exemplo, PubMed Central. Você saúda estas iniciativas?

BR: Estabelecer seu próprio repositório é certamente uma coisa útil para uma agência de fomento. É absolutamente essencial para que eles possuam cópias de toda a literatura produzida a partir da pesquisa que financiaram. Mas esta será sempre uma coleção incompleta do corpus, uma vez que conterá somente os resultados das pesquisas que eles próprios financiaram. Apenas repositórios institucionais podem fornecer cobertura completa.

RP: Essencialmente, você está falando sobre a diferença entre tentar criar um sistema centralizado (quando não há nenhuma autoridade central), em vez de explorar a natureza em rede da web para criar (1) um modelo distribuído com base 
na agregação ao invés de (2) centralização. Você está dizendo que o modelo (1) inevitavelmente proporciona um retrato mais completo?

BR: Sim. E por esta razão repositórios das agências de fomento devem realmente ter um único objetivo, o de colher metadados a partir de repositórios institucionais. Para isso, é claro, seus repositórios terão de ser compatíveis com repositórios institucionais, o que significa que RI também precisam ser construídos com os padrões reconhecidos, e obedecer a certas regras. Por exemplo, precisamos desenvolver padrões bem definidos para que as publicações depositadas, em RI, possam identificar qualquer agência de fomento que tenha dado apoio aos pesquisadores que as produziram.

RP: Os governos têm um papel a desempenhar para facilitar o OA? Em caso afirmativo, qual o papel?

BR: Se eles financiam pesquisas, sim. Da mesma forma, se eles operam esquemas de avaliação de pesquisa para ajudá-los a decidir que subsídios oferecer a instituições de pesquisa também têm um papel a desempenhar.

RP: Estou certo em pensar que você espera persuadir o Fundo Nacional de Pesquisa da Bélgica a considerar a adoção de um mandato $O A$ verde?

BR: Absolutamente, sim. E eu gostaria de vê-lo diretamente conectado com a sua elegibilidade para concessões futuras.

RP: Você está particularmente associado à estratégia da via Verde do OA. Quais são os seus pontos de vista sobre os prós e contras das duas estratégias: Via Verde e Via Dourada?

BR: A estratégia da Via Verde do OA fornece resposta imediata às necessidades da universidade, e de dá visibilidade imediata aos pesquisadores de uma instituição. Se a estratégia da Via Verde cresce de forma constante, como está fazendo atualmente, ele irá conduzir à Via Dourada do OA. Então, para mim, a Via Verde é um caminho para o OA, mesmo que seja difícil de avaliar que tipo de linha de tempo enfrentaremos. 
RP: Os editores muitas vezes argumentam que a estratégia Via Verde do OA ameaça tanto os seus negócios individuais com as publicações acadêmicas/científicas em geral, particularmente se um grande número de artigos são colocadas em acesso livre sem um período de embargo adequado. Você concorda que existem perigos aí? Em caso afirmativo, como podem ser evitados?

BR: Eu não acredito que seja o caso. Alguns exemplos demonstram isto. Certamente, para editores regionais, particularmente, em línguas locais como o francês, é uma grande vantagem. Por exemplo, as editoras de nossa universidade, que eram naturalmente, inicialmente fortemente contrária à minha política de leitura livre, percebeu que o mandato verde OA (ou seja, depositar as publicações em repositórios como ORBi) serviu para ampliar seu perfil em outros países de língua francesa, tais como: a França, Suíça e Canadá/Quebec. Este, por sua vez, aumentou o número de assinaturas junto a pessoas que querem folhear a revista inteira, em vez de ler apenas um único artigo que eles encontraram no ORBi. Este é um efeito inesperado e indireto, mas demonstra que tornar artigos acessíveis livremente não prejudica as vendas. Pelo contrário, aumenta a sua visibilidade fora dos mercados tradicionais.

RP: Em sua visão, qual é o período ideal de embargo?

BR: Pelas razões que descrevi acima, não vejo necessidade de qualquer tipo de embargo. Até hoje, este ponto não foi entendido pelos editores. Eles devem ver a disponibilidade imediata de um artigo, em acesso livre, como um trailer para a venda da revista completa. No entanto, reconheço que os editores verão isto como uma estratégia arriscada, por isso os benefícios terão de ser demonstrados ao longo do tempo. Nesse meio tempo, eu diria que um embargo de seis meses é razoável.

\section{RP: A ULG apoia a estratégia Via Dourada?}

BR: Não de uma forma muito coercitiva. No entanto, oferecemos a oportunidade de publicar trabalhos em OA diretamente através do PoPuPS. 
RP: Isto seria o Portal for Publication of Scientific Journals? Eu estaria correto em pensar que PoPuPS é uma plataforma de publicação desenvolvida para permitir aos pesquisadores da ULG publicar seus próprias periódicos?

BR: Sim. Já existem 13 revistas aderentes à estratégia Via Dourada do OA em linha. E desde 2006 operamos também um programa chamado Bictel/e. Este é um repositório de teses da ULG. Todas as nossas iniciativas OA estão descritas na web. A propósito, nós apoiamos também, financeiramente, quaisquer autores que queiram publicar em revistas de acesso livre, tais como aqueles publicados pelo BioMed Central (BMC).

RP: Você quer dizer que a Universidade de Liège tem um fundo de apoio à Via Dourada $\mathrm{OA}$, ou que se inscreve em programas de afiliação operados por editoras OA como BMC, que permite que pesquisadores publiquem em revistas $O A$, sem qualquer custo para si mesmo, ou pelo menos a uma taxa reduzida?

BR: Nós temos um fundo OA limitado, mas nós, de fato, compramos opções de desconto junto ao BMC, e usamos o fundo para apoiar os nossos pesquisadores que publicam em revistas do BMC.

RP: Você também é presidente da organização Enabling Open Scholarship (EOS), que foi lançado em setembro de 2009. Qual é o propósito e missão da EOS, e quais os resultados obtidos até hoje?

BR: A EOS se propõe a convencer os líderes universitários de todo o mundo da necessidade do acesso livre (OA) e ensiná-los como proceder. Além de algumas "conversões" não temos tido muito sucesso até agora. Mas só muito recentemente a EOS tornou pessoa jurídica de direito belga (na verdade, o processo não está totalmente concluído até o momento), então as nossas atividades têm sido um pouco limitadas até esta data.

RP: O que os dirigentes de universidade precisam saber sobre o OA, e como a EOS procede?

BR: Eles têm que entender o quanto é importante, para a sua instituição, se libertar do pesado fardo de pagar demais para manter as coleções de revistas científicas em 
suas bibliotecas, especialmente à luz da atual explosão de preços em tais publicações. E eles têm que entender que seus pesquisadores produzem, controlam a qualidade e consumem conhecimento. Mas enquanto esses pesquisadores contribuem em todas as três etapas do processo, as instituições acabam pagando pelo conhecimento, pelo menos duas vezes.

RP: Você quer dizer que as instituições de pesquisa (muitas vezes financiadas pelos governos) criam o conhecimento, em primeiro lugar, seus pesquisadores, então, produzem os documentos e realizam a revisão pelos pares, mas as instituições têm que comprar de volta o conhecimento dos editores na forma de assinaturas de revistas?

BR: Exatamente! Os dirigentes de universidades também precisam perceber que a Via Verde do OA é o caminho para se alcançar a Via Dourada do OA. E eles devem ver o benefício para os seus pesquisadores e para a sua instituição ao colocar à sua disposição, uma vitrine para o seu trabalho, depositando-os em seus RI. É inconcebível nos dias de hoje que uma instituição possa permanecer Inconsciente da maioria da produção de suas próprias pesquisas publicadas. Nenhuma fábrica iria aceitar isso. Aqueles que não têm interesse em OA, por si só, deveriam pelo menos ver o valor, para uma universidade, da manutenção de um inventário dos trabalhos que produz. Finalmente, eles devem compreender que o RI pode agregar uma grande contribuição para a reputação da sua instituição.

RP: Que tipo de resposta que você obtém de suas contrapartes em outras universidades, quando você fala a eles sobre o OA?

BR: Cinco anos atrás, eu costumava ter uma recepção muito positiva. Eu diria que foi barulho demais - e para que benefício? Hoje, no entanto, há um grande interesse - na Bélgica, França, Itália, Espanha e Portugal, até o momento. Outros reitores e vice-chanceleres devem agora se unir todos para tornar o movimento irresistível.

RP: Em sua opinião, hoje, quais são os principais obstáculos ao OA? 
BR: Os obstáculos que eu vejo são: a insuficiente mobilização por parte de dirigentes universitários (e centro de pesquisa) em favor da causa; pesquisadores com medo das questões jurídicas levantadas pelo OA; pesquisadores preocupados que o OA signifique desistir de publicar em revistas de prestígio ou com uma grande reputação ou em revistas que eles possam conhecer seus trabalhos e que serão vistos por seus colegas em todo o mundo, e que têm um alto fator de impacto e assim por diante. Isto significa que o que é necessário é uma transformação na cultura atual de avaliação. Só então podemos esperar que as coisas mudem drasticamente.

RP: O que você diria que aprendeu com sua experiência de introduzir o OA na Universidade de Liège?

BR: Desenvolvi uma visão mais ampla sobre os princípios de publicação. Levaria muito tempo para explicar aqui, mas construi uma filosofia pessoal sobre o tema. E isso me levou a repensar completamente os objetivos e métodos de comunicar o progresso da ciência e do conhecimento. Espero um dia ser capaz de explicá-1o mais claramente. Talvez quando eu me aposentar escreva um livro sobre o assunto!

RP: Quando e como você acha que a comunidade de científica vai atingir o OA universal?

BR: Universal OA levará muito mais tempo do que eu pensava antes. Mas cada passo é útil em si mesmo.

RP: De que maneira você espera que a pesquisa mudará, no mundo, com o OA universal?

BR: Este é um tópico muito amplo para discutir, e vale à pena um segundo livro! Mas eu acredito que ele vai proporcionar maior transparência à ciência, especialmente quando vier o open data. Espero uma tremenda mudança na forma como fazer pesquisa, e disseminá-la. Na verdade, não apenas uma mudança. Mas, uma revolução global.

RP: Finalmente, em uma nota pessoal, o seu colega - e EOS convenor - Alma Swan me disse que você é jardineiro cuidadoso e um excelente fotógrafo. Gostaria de saber se essas habilidades 
teriam desempenhado algum papel na sua conversão OA: cada jardineiro quer uma boa loja para seus produtos acho, e cada fotógrafo quer ter um portfólio de seu trabalho para mostrar seus talentos. Eu estou no caminho certo?

BR: Você está completamente errado sobre a jardinagem. Eu, ocasionalmente, só ajudo a minha esposa! Entretanto, amo fotografia, contudo, "excelente" pode ser um exagero (Obrigado Alma!). E, concordo que eu tenha um sistema de arquivamento perfeito para as dezenas de milhares de fotos que tirei ao longo dos últimos 43 anos, e são poucas aquelas que eu não seria capaz de encontrar facilmente. Dito isto, eu antecipei o depósito de quase todos os meus trabalhos científicos de um longo período de tempo no repositório. Felizmente, agora se tornou uma realidade e eu gostaria que estivessem disponíveis todo esse tempo. Você sabe que eu estou convencido de que os cientistas, hoje, são mimados pela escolha, quando chegam ferramentas, disponíveis, como agora, (incluindo ser capaz de saber a qualquer momento quem está citando o seu trabalho e como), e eu só queria que eles percebessem, plenamente, quão agradável e útil é tê-los. Eu mesmo sou um blogueiro e um tweeteiro, por isso estou realmente convencido de que há um novo campo de comunicação aberto para a ciência, e estamos apenas testemunhando o seu início ...

RP: Essa é uma boa nota para terminar. Eu só quero acrescentar que as suas fotografias são realmente fantásticas. Gostei especialmente da foto dos três homens escavando as ruas de Londres, em 1975, para colocar tubulações. Talvez seja essa a situação que o movimento OA se encontra atualmente: no processo de criação da infraestrutura necessária para a revolução global na comunicação científica a que você se refere. E que, às vezes, exige sujar as mãos, aceitando o fato de que as pessoas tendem a se queixar do incômodo provocado por este trabalho, e temem que possam cair em um dos buracos temporários. Mas desde que OA é uma causa de valor, tais inconvenientes apenas deverão de ser tolerados. Ah, e como todos os grandes projetos de construção, a tarefa sempre leva muito mais tempo do que o inicialmente previsto.

RP: Obrigado por ter tempo para falar comigo, e se divertir no jardim! 